\title{
CONGENITAL MITRAL STENOSIS
}

\author{
BY \\ C. ELAINE FIELD, M.D., \\ Resident Medical Assistant and Clinical Pathologist, \\ Hospital for Sick Children, Great Ormond Street
}

Congenital mitral stenosis is a rare malformation of the heart and is nearly always associated with other anomalies in the heart or vessels.

Cowan and Ritchie (1935) found no example in their post-mortem series of 101 cases of chronic mitral valvular disease, but Farber and Hubbard (1933) report three out of fourteen cases of foetal endomyocarditis. In Maud Abbott's (1931) series of 1,000 cases of congenital heart disease twenty-three were present, of which only six could be classified as the primary lesion, the remainder complicating other grosser defects. Analysing these six cases, Maud Abbott found the average age to be five-and-a-half years and the oldest twenty-seven years. The commonest associated anomaly was a patent ductus arteriosis with hypoplasia of the aorta. Cyanosis was variable and dyspnoea a common symptom ; clubbing was detected only in one, but delayed development in four out of the six cases. The physical signs were variable, the commonest being an apical systolic murmur. In only one case was the full picture of thrill and pre-systolic murmur detected. Death was commonly of sudden onset and post-mortem examination revealed hypertrophy of the right side of the heart.

Investigation of the post-mortem records of the Hospital for Sick Children, Great Ormond Street, dating from 1860 (see table) showed 250 cases of congenital heart disease, seven of which revealed stenosis of the mitral valve. In only one case could it be described as the primary lesion (Newns, 1938), this showing the characteristic enlarged left auricle and right side of the heart. There was no other congenital defect, death being due to sudden collapse after a blood transfusion. Of the remaining six cases, two showed an aplasia of the whole of the left side of the heart ; one an undeveloped left ventricle with patent ductus arteriosis ; one was associated with a large patent interventricular septum, and two with tricuspid stenosis and evidence of foetal endocarditis in the form of a fringe of vegetations on the valves. It is interesting to note that the average age in this series of cases was six months and 86 per cent. were male infants. 


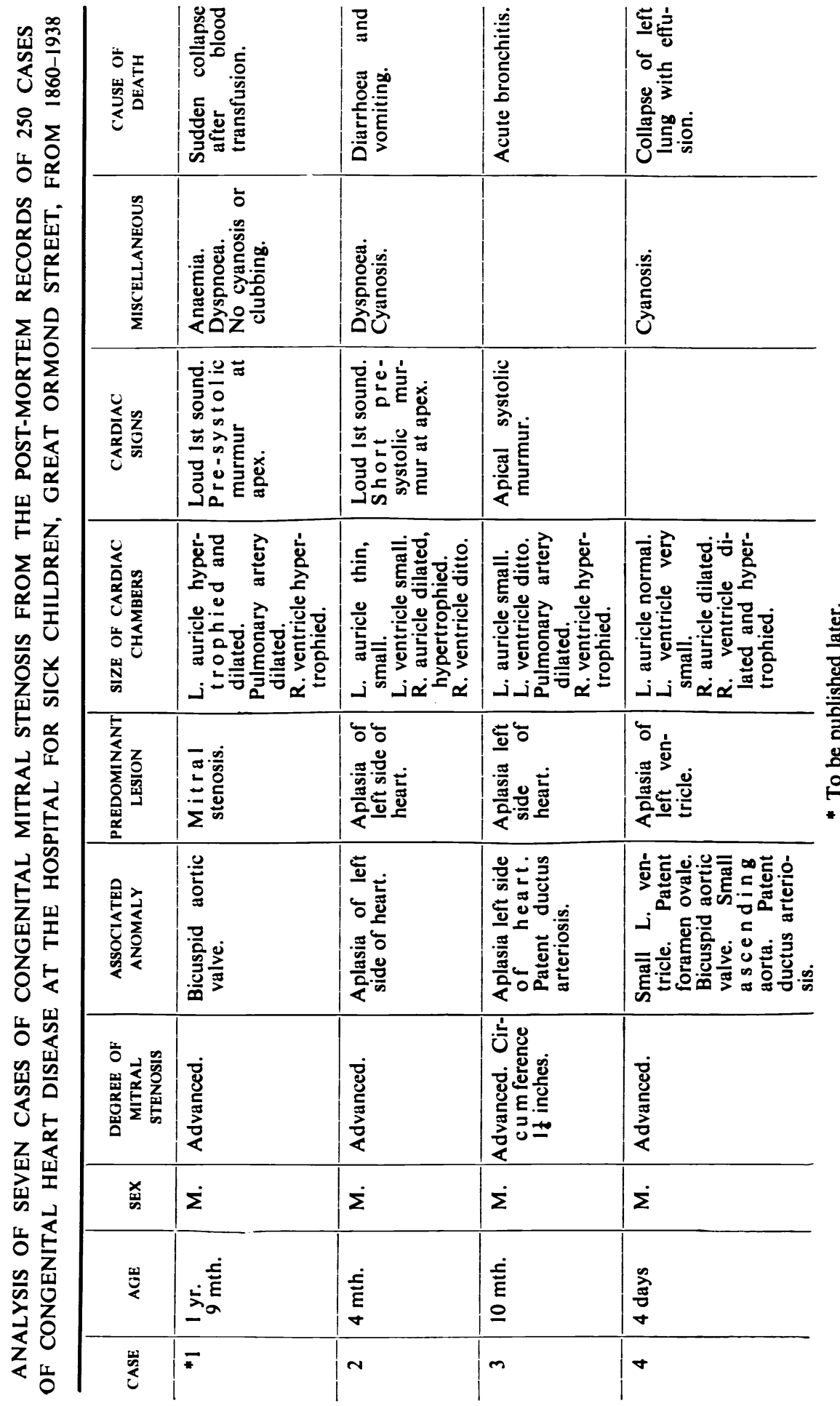




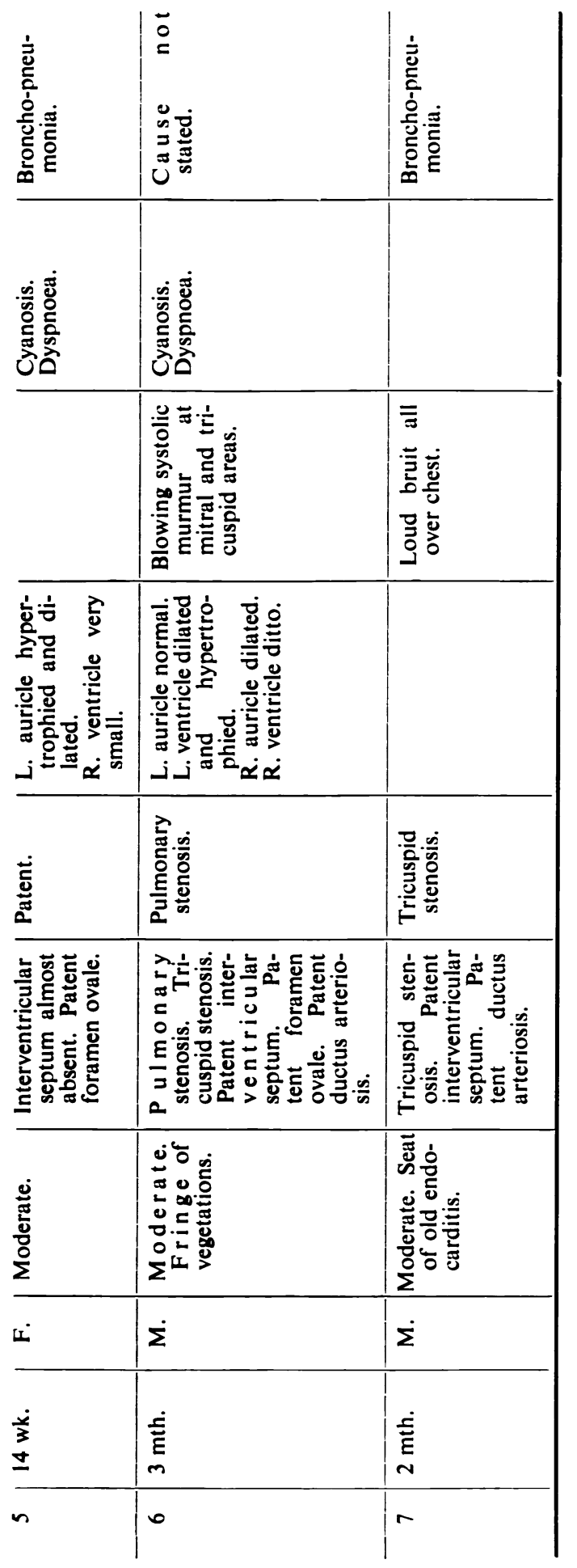




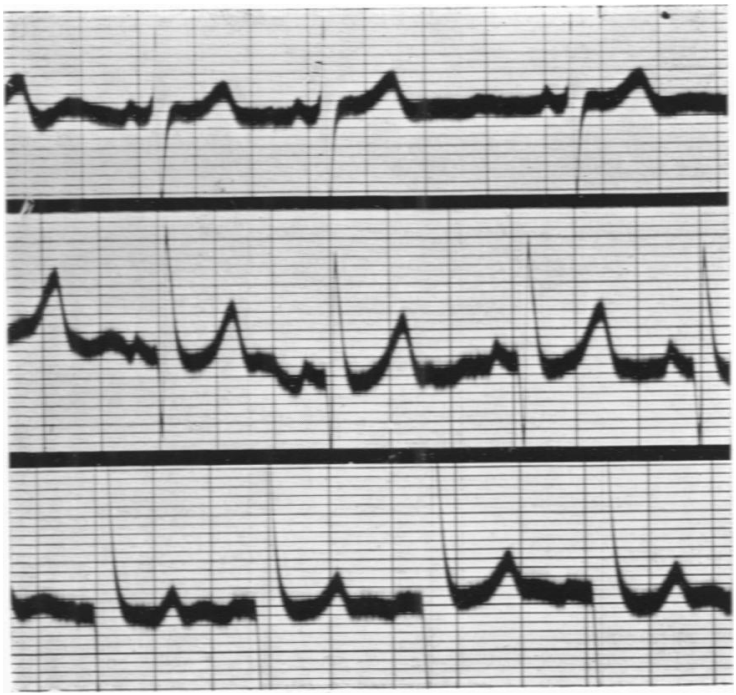

FiG. 1.-Electrocardiogram 1935.

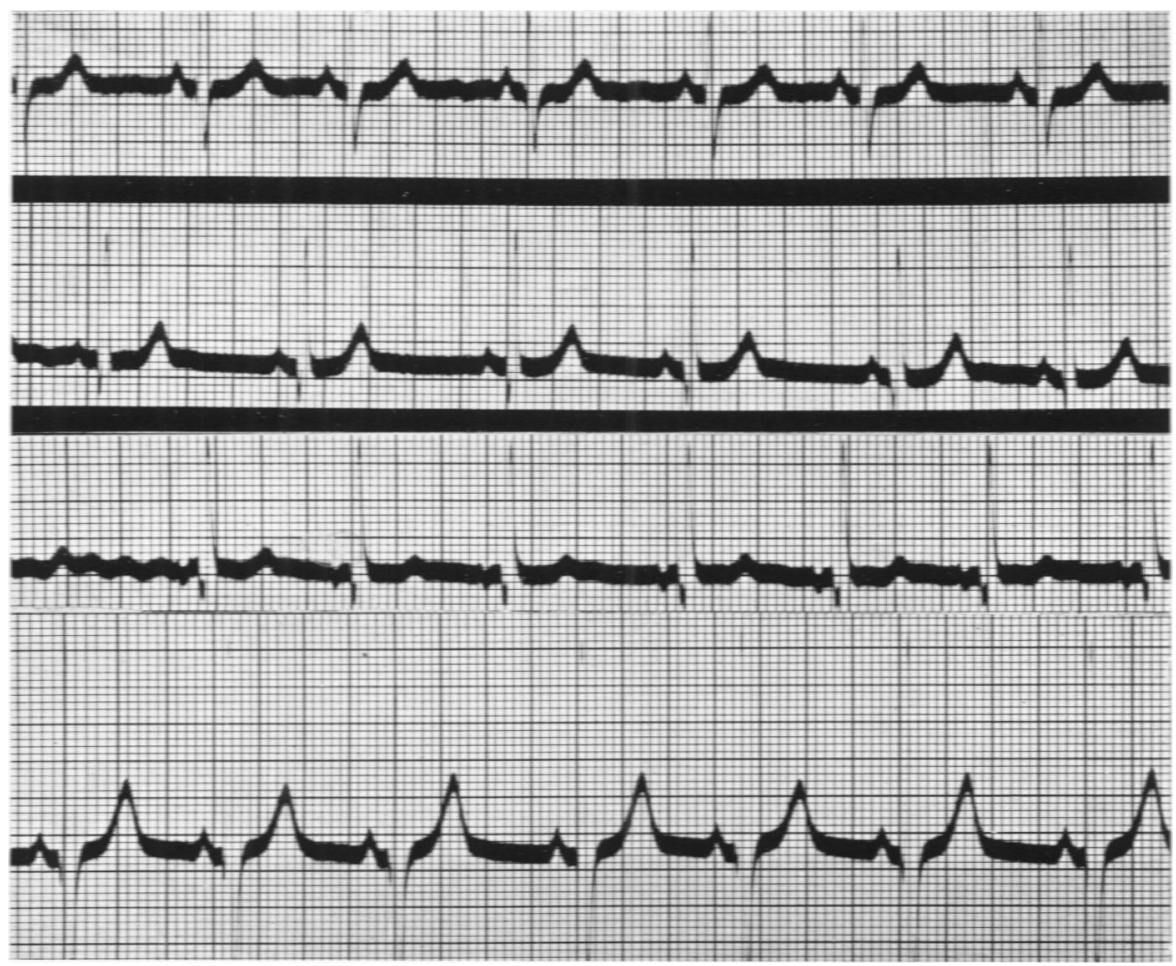

FiG. 2.-Electrocardiogram 1938. Some $R$. ventricular preponderance. Sharp $P$ waves in leads 1 and 2, inversion of $P$ in lead 3. Well marked $Q$ waves in leads 2 and 3. Lead 4 is normal. 


\section{Case record}

History. A male child aged six years and four months was first sent to the Out-patient Department at Great Ormond Street with the history of coughing since birth and repeated vomiting. He had also had attacks of panting and turning purple over the forehead. Delivery was normal but three weeks premature, and the mother states that when three months pregnant she had a severe shock with a gas explosion. Birth weight was $5 \mathrm{lb} .10 \mathrm{oz}$. and the child was breast fed for four months. At three weeks jaundice was first noticed and persisted until four months old, followed by an attack of

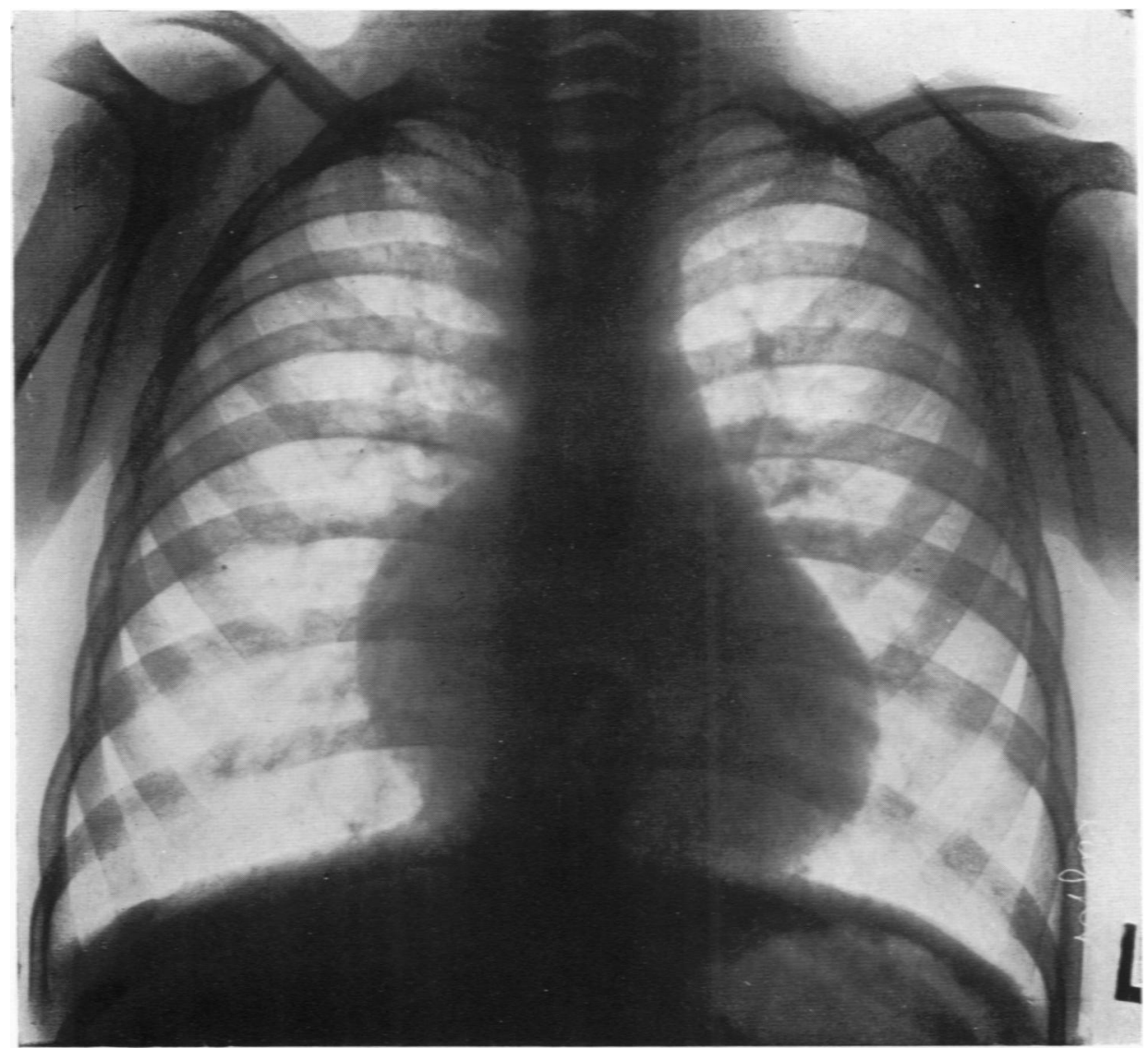

Fig. 3.-Antero-posterior X-ray of the heart showing enlargement of the right side.

gastro-enteritis and later marasmus for which he was treated in several hospitals. It was at this time that signs of congenital disease of the heart were first detected with a systolic thrill and bruit at the pulmonary area also perceptible to a lesser extent over the praecordium. He was discharged from hospital at ten months old weighing $9 \mathrm{lb}$. and in a fair condition. No further panting attack occurred and progress was uneventful until three-and-a-half years of age, when he again attended the Out-patient Department at Great Ormond Street under Dr. D. Paterson for bilious attacks and diarrhoea. He was sent to see Sir Thomas Lewis at University College Hospital, who, in a personal 
communication, reported the following: 'He seems to have little or no enlargement of the heart. The murmur is difficult to time, I make the main murmur diastolic. Stenosis of the mitral valve at this age is so rare that I hesitate very much to diagnose. I have heard no murmur like it in a child

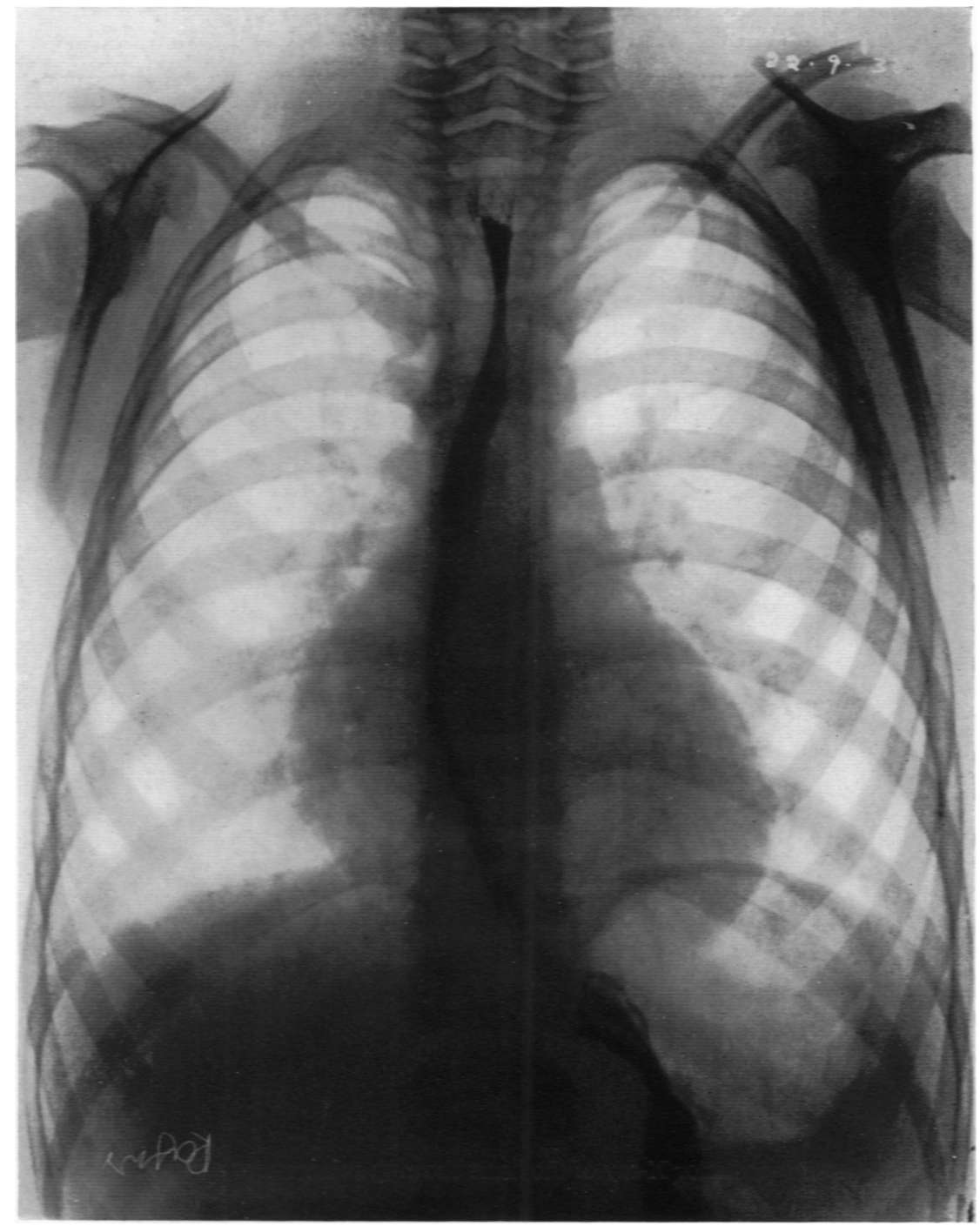

FIG. 4.-Antero-posterior X-ray of the heart during a barium swallow showing slight compression and deviation of the oesophagus to the right by the enlarged left auricle.

before. The electrocardiographic report (see fig. 1) shows gross sinus arrhythmia and extraordinary Q waves in leads II and III.'

In July, 1938, he was again fully investigated. He had suffered from whooping cough and measles the previous year, but no evidence of rheumatism in the form of pains in the limbs. His chief complaint at this time was cough with breathlessness on running or jumping, but no cyanotic attacks. There 
was nothing relevant in the family history except the father who suffered from vague rheumatic pains.

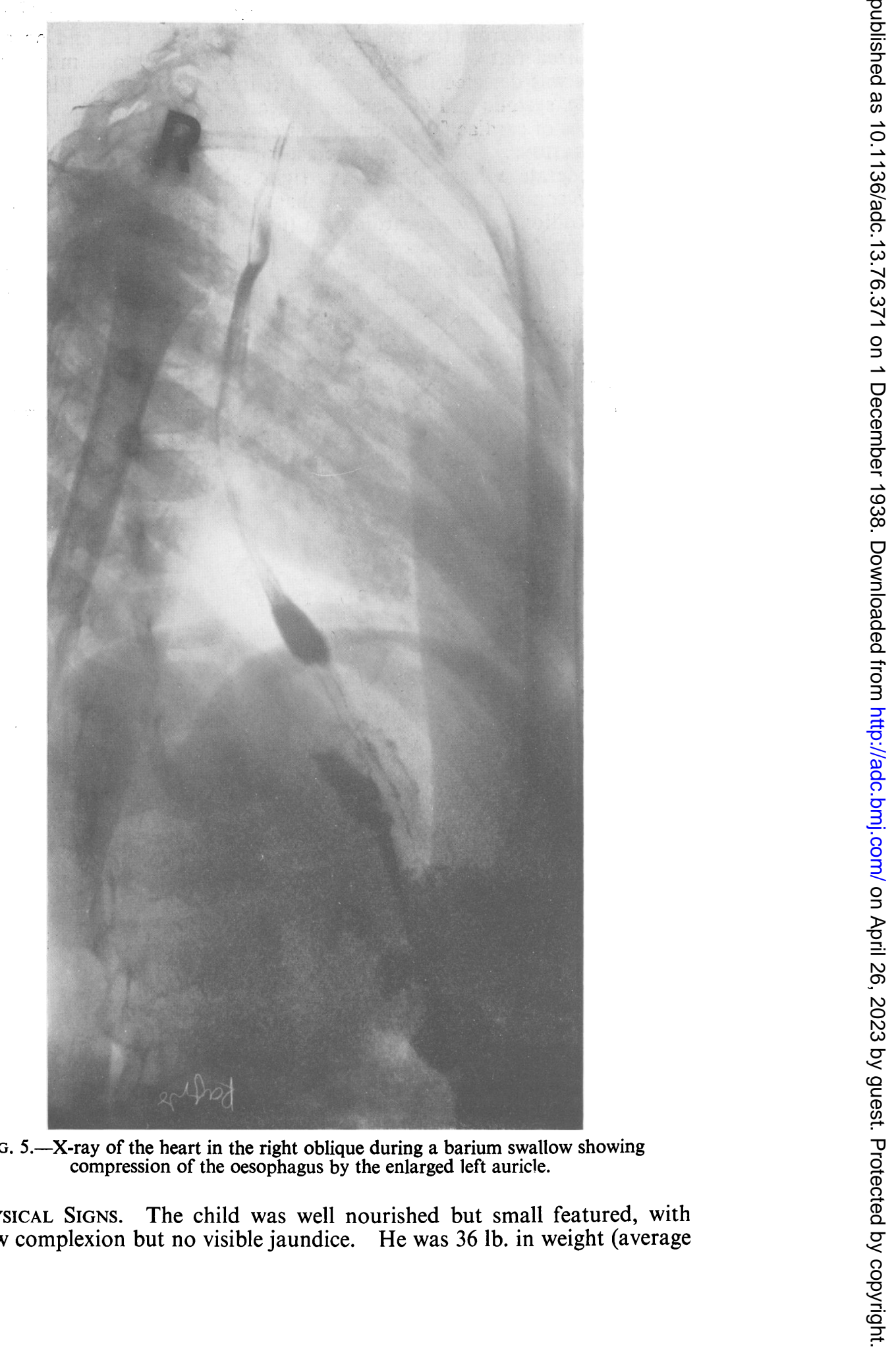


for age, $46 \mathrm{lb}$.) and had a spinal scoliosis with prominence of the right chest in front. There was no cyanosis or clubbing. The heart was enlarged to the right $1 \frac{3}{4}$ inches from the mid-line ; the apex beat being visible in the fifth space three inches from the mid-line. A thrill could be felt and on auscultation a localized full diastolic with characteristic pre-systolic murmur heard. No dullness was detected in the second left intercostal space. Blood pressure $104 \mathrm{~mm}$. Hg. systolic and 56 diastolic ; heart rate 82 beats a minute. There were no signs of cardiac failure or venous congestion.

INVESTIGATIONS. X-ray and screening of the heart (fig. $3,4,5$ ) showed moderate enlargement of the right side and also of the left auricle detected by compression of the oesophagus in the left oblique and anteroposterior positions. Electrocardiogram (fig. 2) showed some right ventricular preponderance ; sharp $P$ waves in leads 1 and 2 , inversion of $P$ in lead 3 ; well-marked $Q$ waves in leads 2 and 3 ; lead 4 is normal. Dr. B. E. Schlesinger reported as follows: ' E. C. G. would fit in with congenital mitral stenosis and confirms the clinical signs and X-ray.' Blood count R.B.C. 4,020,000 per c.mm. W.B.C. 12,900 . Hb. 70 per cent. Sedimentation rate 11 . Van den Bergh-direct reaction negative. Indirect reaction very faint trace. Mantoux tuberculin reaction $1 / 1000$, negative.

Conclusion. Taking into consideration the history and physical signs with support from the $x$-ray and electrocardiogram, a diagnosis of congenital mitral stenosis in this case during life appears to be fully justifiable. case.

Thanks are due to Dr. Donald Paterson for permission to publish this

\section{REFERENCES}

Abbott, M. (1931). Nelson's Loose Leaf Medicines, 4, 207.

Cowan, J., and Ritchie, W. T. (1935). Diseases of the Heart.

Farber, S., and Hubbard, J. (1933). Amer. J. Med. Sci., 136, 705.

Newns, G. H. (1938). Proc. roy. Soc. Med., 31, 229. 